\title{
Dissection of intercostal nerves by means of assisted video thoracoscopy: experimental study
}

\author{
Juan Pablo Cáceres ${ }^{1 *}$, Santos Palazzi ${ }^{1}$, Jose Luis Palazzi ${ }^{1}$, Manuel Llusá², Sanz M³ \\ and Varci $S^{1}$
}

\begin{abstract}
In total brachial plexus preganglionic lesions (C5-C6-C7-C8 and T1) different extraplexual neurotizations are indicated for partial motor function restitution. Mostly for the flexion of the elbow. Neurotization with intercostal nerves (ICN) to musculocutaneous nerve has been known and accepted during many years with different results 2 - 5. The customary technique as described by various authors is carried out by means of a large submammary incision to harvest three or four intercostal nerves (Figure 1). Then are connected by direct suture or grafts to the musculocutaneous nerve or its motor branches 6 - 7. In this article the authors described the possibility of dissection intercostal nerves by means of assisted video thoracoscopy. (VATS-videdo assisted thoracic surgery).
\end{abstract}

\section{Background}

In total preganglionic lesions (C5-C6-C7-C8-T1) of the brachial plexus different extraplexual neurotizations are indicated. Mostly to reinervate total or partially the flexion of the elbow. Neurotization of the musculo cutaneous nerve by intercostal nerves (ICN) is a well known technique accepted with different outcomes [1,2]. The technique described by some authors is carried out by means of a large submammary skin incision (Figure 1) in order to obtain the third, fourth and fifth ICN. These ICN are drived to the musculo cutaneous nerve or it motor branches (biceps brachii muscle and brachialis muscle) and suture them directly or by grafts $[3,4]$. Based by previous authors $[5,6]$ we describe the possibility of dissection and harvesting intercostal nerves by means of assisted video thoracoscopy (VATS-VIDEO ASSISTED THORACIC SURGERY) [5-8].

\section{Material and methods}

The surgical method was planned in two groups, the first one in three cadavers (6 hemithorax) and the second group in three live pigs (mini-pigs breed of 30-40 Kgs. weight.

\section{Group 1 cadaver}

The trunk lays in lateral decubitus. Three portals of access are used. First trocar of diameter $10 \mathrm{~mm}$ at the level of the

\footnotetext{
* Correspondence: 26977jcl@comb.cat

${ }^{1}$ Centro Médico Teknon, Barcelona, Spain

Full list of author information is available at the end of the article
}

posterior axillary line: By this portal a fibroscopy with lens at $30^{\circ}$ are introduced. Second trocar in the posterior scapular region. Third trocar at 3 or $4 \mathrm{~cm}$ parallel and anterior to the first access (Figure 2).

Prior of the dissection we localize the intercostal space between the third and fourth rib by an external puncture with a rachidian needle.

The internal mammary artery is taken as reference for the anterior limit of the dissection.

Incision the parietalis pleura, identification of the intercostal nerve and dissect it up to the axillary medial line. The same process is repeated for the next nerves until three or four of them are harvested.

Once freeded the nerves are externalised by a small incision at axillary level. At this point are used for the neurorraphy to the musculo cutaneous nerve.

Time employed: $30^{\prime}-1 \mathrm{~h}$ for each hemithorax. (3 intercostal nerves).

\section{Group 2 (experimental animal)}

Animals employed are male mini-pigs breed of $30-40$ Kgs of weight. Well prepared operating theatre for experimental surgery and thoracoscopy tools [9-12].

The animal with selective endotracheal intubation lays in lateral decubitus. Three portals of access: a trocar of $10 \mathrm{~mm}$ for the thoracoscopy. Two of $5 \mathrm{~mm}$ for the surgical instruments (Figure 3) (hook and scissors with microcoagulation). 


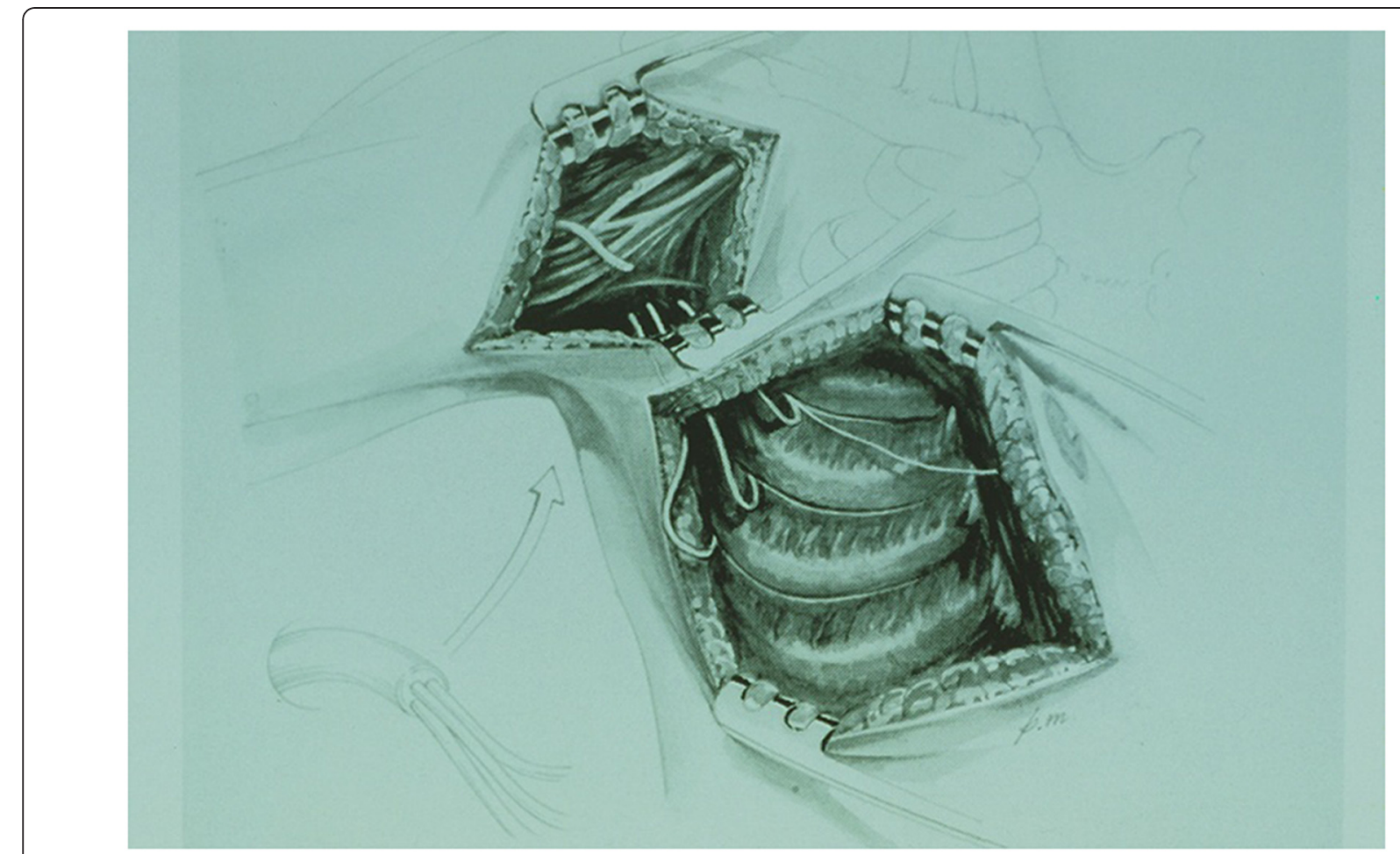

Figure 1 Submamry incisión for disecction intercostal nervs.
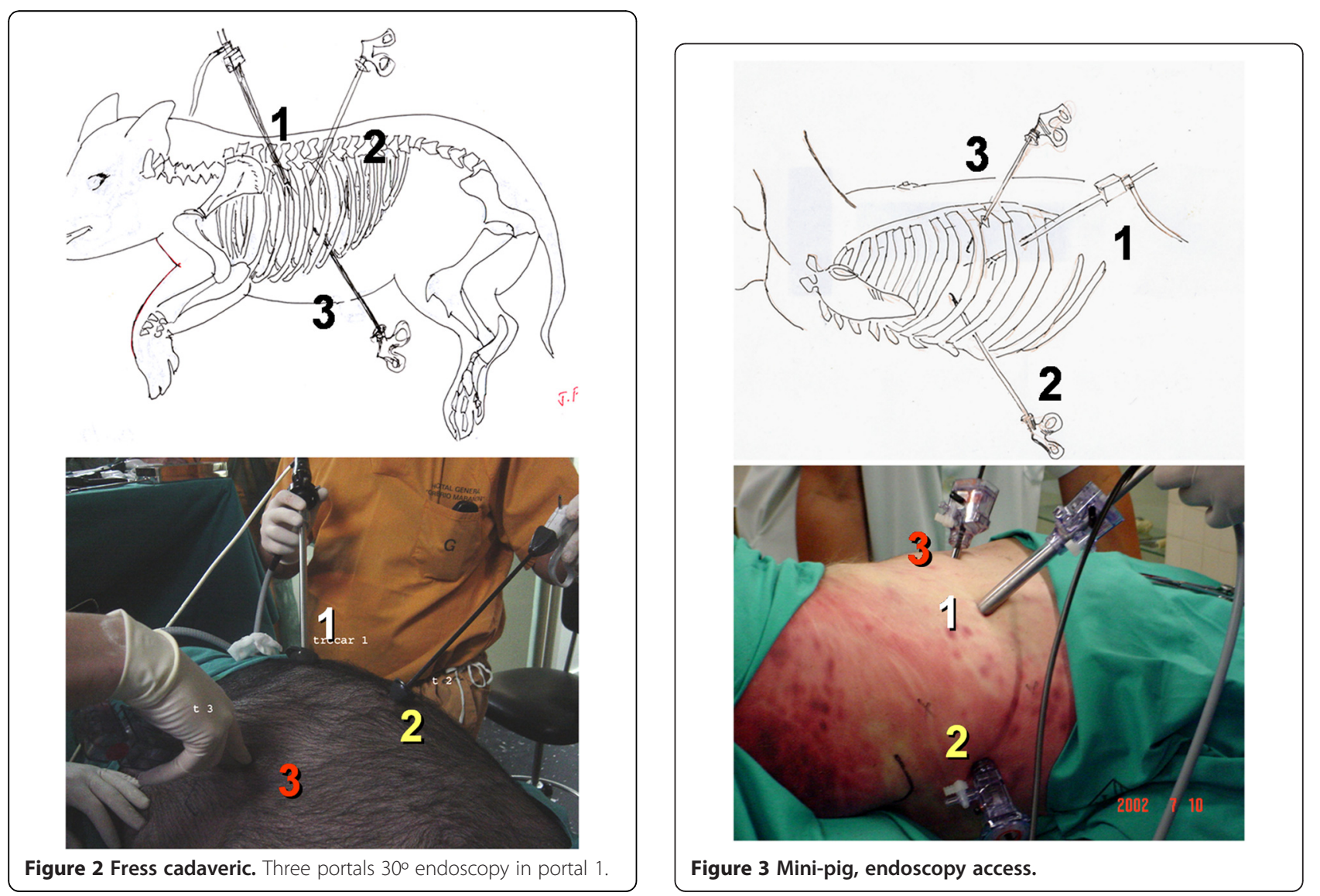
Dissection is realised at parietalis pleura after identification of the desired intercostal level.

Coagulation of intercostal vessels previous to the section of the nerve as anterior as the internal mammary artery allows it.

Same procedure is repeated until 3 or 4 nerves are harvested. Externalisation of them and glued by fibrine-glue so there are ready for nerve connection to the target. Normally the musculo cutaneous nerve or it motor branches. Animals were euthanized after the surgery to obtain information about the procedure.

Time employed $1-2 \mathrm{~h}$ in each hemithorax.

\section{Conclusions}

In absence of previous studies concerning harvesting the intercostal nerves by VATS we demonstrated that there is a possibility to do that. In humans ICN III, IV, V are currently employed for neurotization of biceps muscle. ICN VI, VII for triceps. There are other options in total preganglionic lesions of the brachial plexus using parts (C7) of contralateral brachial plexus.

Solid clinical rules for harvesting intercostal nerves by means of VATS has still to be established.

\section{Author details}

${ }^{1}$ Centro Médico Teknon, Barcelona, Spain. ${ }^{2}$ Faculty of Medicine, Barcelona, Spain. ${ }^{3}$ Department Experimental Surgery, Hospital Gregorio Marañón, Madrid, Spain.

\section{References}

1. Bolouedine $M$, Allieu Y: Intercostal nerve transfer classification. Chir Main 2001, 20(2):136-7.

2. Kawabata H, Shibata T, Matsui $Y$, Yasui N: Use of intercostal nerves for neurotization of the musculocutaneous nerve in infants with birthrelated brachial plexos palsy. J Neurosurgery 2001, 94(3):386-391.

3. Malessy MJA, Thomeer RTW: Evaluation of intercostals to musculocutaneous nerve transfer in reconstructive brachial plexus surgery. J Neurosurg 1988, 88:266-271.

4. Terzis JK, Papakonstantinou KC: The surgical treatment of brachial plexus injuries inadults. Plast Reconstr Surg 2000, 106:1097.

5. Bolotin G, Lazarovici H, Uretzky G, Zlotnick AY, Tamir A: Saute Mthe efficacy of intraoperative internal intercostal nerve block during video-assisted thoracic surgery on postoperative pain. Ann Thorac Surg 2000, 70(6):1872-1875

6. Yu-Dong Gu MD, Jian-Jun Ma MD: A comparative study of nerve reconstruction techniques in phrenic nerve transfer for treatment of brachial plexus root avulsion injuries. Hand Surg 1997, 2:25-33.

7. Shi QL, Gu YD: A cadaveric study of intrathoracic harvesting of phrenic nerve Ander endoscope. Chin J Hand Surg 1999, 15:104.

8. Wen-Dong X, Yu-Dong Gu, Jian-Guang Xu, Li-Jie Tan: Full-Length phrenic nerve transfer by jeans of video-assisted thoracic surgery in trating brachial plexos avulsion injury. Plastic and recosntructive surgery 2002, 104-109.

9. Frandson \& Spurgeon: Anatomía y Fisiología de los animales domésticos. Interamericana. Mc Graw-Hill: Interamericana-McGraw-Hill; 1995:560.
10. Huerta MC, Villazon O, Acevedo A, Gonzalez M, Moscoso B: Ventilación mecánica selectiva y manejo anestésico en cirugía toracoscópica videoasistida. Asociación Mexicana de cirugía endoscópica 2001, 2:87-96.

11. Sack WO: Essential pig anatomy. Ithaca. New York: Veterinary Textbooks; 1999.

12. Smallwood JE: In A guided tour veterinary anatomy: domestic ungulates and laboratory mammals. Edited by Saunders WB. Philadelphia: W.B. Saunders Company; 1992. vii, 390 p. ill., 27 cm.

doi:10.1186/1749-7221-8-3

Cite this article as: Cáceres et al: Dissection of intercostal nerves by means of assisted video thoracoscopy: experimental study. Journal of Brachial Plexus and Peripheral Nerve Injury 2013 8:3.

\section{Submit your next manuscript to BioMed Central and take full advantage of:}

- Convenient online submission

- Thorough peer review

- No space constraints or color figure charges

- Immediate publication on acceptance

- Inclusion in PubMed, CAS, Scopus and Google Scholar

- Research which is freely available for redistribution 